\title{
Evaluasi Tata Kelola Teknologi Informasi Universitas Multimedia Nusantara Periode 2016
}

\author{
Wella $^{1}$, Stella Aprilia Sirapanji ${ }^{2}$ \\ Sistem Informasi, Fakultas Teknik dan Informatika, Universitas Multimedia Nusantara \\ Tangerang, Indonesia \\ wella@umn.ac.id ${ }^{1}$, ellasirapanji@gmail.com² \\ Diterima 3 Oktober 2016 \\ Disetujui 7 November 2016
}

\begin{abstract}
Not only for enterprises, educational institution use information technology for teaching and learning. Universitas Multimedia Nusantara (UMN) aware that IT is very important in the world of education. To measure effectiveness in IT governance, UMN needs audit information system using the COBIT 5.0 framework in order to determine the extent to which the performance of the IT department and also know the UMN produce a solution to every problem is unresolved. The object of this study is the Department of Information Technology UMN. This study uses COBIT 5.0 with 5 domains that is Evaluate, Direct and Monitor (EDM); Align, Plan and Organize (APO); Build, Acquire and Implement (BAI); Deliver, Service and Support (DSS) and Monitor, Evaluate and Assess (MEA). At 37 the process of the 5 IT governance domains belonging to COBIT 5.0 by using the stages of COBIT 5.0 is filtered into 10 processes. The data collection was done by interviewing the manager of IT department, observation of documentation, and the distribution of questionnaires to the two heads of divisions within the IT department manager for IT departments demand UMN. The results of this study each domain is at $1^{\text {st }}$ level (incomplete). Capability level values achieved by EDMO1 is $81.84 \%$, EDM02 is $76.17 \%$, $A P O 01$ is $73.28 \%$, APO02 is 67.72\%, APO03 is 52.30\%, APO05 is 66.44\%, APO07 is 64.20\%, APO08 is 75.19\%, BAI01 is 56.33\%, and BAIO2 is $65.20 \%$.
\end{abstract}

Keyword: Audit Information System, Capability Level, Framework COBIT 5.0, IT Governance.

\section{PENDAHULUAN}

Perkembangan teknologi informasi menjadi sangat penting bagi setiap perusahaan, termasuk institusi pendidikan salah satunya adalah UMN. Untuk itu UMN memerlukan tata kelola dan manajemen yang mapan terutama pada sistem Departemen Teknologi Informasi (TI). Departemen TI menjadi salah satu bagian penting dalam menunjang pertumbuhan UMN kedepannya. Karena hal tersebut maka perlu dilakukan audit Sistem Informasi menggunakan framework COBIT 5.0 untuk melihat sejauh mana performa dari Departemen TI UMN dan juga menghasilkan solusi untuk setiap permasalahan yang belum terpecahkan.

Tujuan dari penelitian ini adalah mengukur tingkat kapabilitas dan untuk memberikan hasil temuan, dampak dan rekomendasi atas pengukuran tingkat kapabilitas dengan objek penelitiannya adalah Departemen Teknologi Informasi di Universitas Multimedia Nusantara dan penelitian ini menggunakan framework COBIT 5.0 sebagai acuan penelitian.

\section{LANDASAN TEORI}

Penelitian yang dilakukan ini memiliki persamaan dengan penelitian terdahulu yaitu, penelitian yang dilakukan oleh Amnah [1]. Penelitian Amnah [1] memiliki judul Analisa Proses Audit Sistem Informasi Biro Manajemen Asset dan Logistik Menggunakan Framework COBIT 4.1 pada Institut Informatika dan Bisnis Darmajaya Bandar Lampung. Penelitian yang dilakukan Amnah [1] ini menggunakan framework COBIT 4.1, tahapan audit Gallegos, dan menggunakan proses PO5, PO7, AI2, dan ME2 dengan hasil penelitian yaitu tingkat kematangan pada Institut Informatika dan Bisnis tersebut berada pada level 4 dan apa yang diharapkan oleh manajemen rata-rata sudah terpenuhi dan dijalankan. Pada penelitian Amnah [1], penulis mengadopsi tahapan audit digunakan yaitu tahapan audit Gallegos [2].

Perbedaan penelitian ini dengan penelitian terdahulu tersebut adalah penulis meneliti pada tata kelola Departemen Teknologi Informasi di Universitas Multimedia Nusantara yang menggunakan framework COBIT terbaru yaitu COBIT 5.0. Penulis juga hanya berfokus pada 10 proses COBIT 5.0 yaitu, EDM01, EDM02, APO01, APO02, APO03, APO05, APO07, APO08, BAI01, BAI02, sedangkan penelitian Amnah [1] menggunakan framework COBIT 4.1 dan hanya berfokus pada 4 proses COBIT 4.1 .

\section{Metode PENELITIAN}

Metode penelitian yang digunakan untuk melakukan pengukuran kapabilitas tata kelola dan manajemen teknologi informasi ini adalah metode COBIT 5.0, dengan objek penelitiannya adalah Departemen TI Universitas Multimedia Nusantara (UMN) dimana merupakan sebuah lembaga perguruan tinggi dengan teknologi informasi dan 
komunikasi sebagai dasar dalam setiap proses belajar mengajarnya.

Selain itu, penelitian ini menggunakan tahapan audit dari Gallegos [2] yaitu:

1. Perencanaan (Planning)

Tahap perencanaan yang akan dilakukan adalah menentukan objek yang akan diaudit yaitu Departemen TI Universitas Multimedia Nusantara kemudian standart evaluasi dari hasil audit dan komunikasi dengan manajer pada departemen TI UMN dengan menganalisa visi, misi, sasaran dan tujuan objek yang diteliti serta strategi, kebijakankebijakan yang terkait dengan pengolahan investigasi.

2. Pemeriksaan Lapangan (Field Work)

Pada tahap ini akan dilakukan pengumpulan informasi yang dilakukan dengan cara mengumpulkan data dengan pihak-pihak yang terkait. Hal ini dapat dilakukan dengan menerapan berbagai metode pengumpulan data yaitu: wawancara dengan manajer TI, memberikan kuesioner dan melakukan observasi langsung ke lokasi ruang kerja departemen TI. Setelah proses pengumpulan data, maka akan didapat data yang akan diproses untuk dihitung berdasarkan perhitungan tingkat kapabilitas. Berdasarkan hasil perhitungan tingkat kapabilitas akan mencerminkan kinerja departemen saat ini.

3. Pelaporan (Reporting)

Pada tahap ini akan memberikan informasi berupa hasil-hasil dari temuan audit dari tahap sebelumnya, kemudian memberikan gambaran jika temuan audit tersebut tidak segera di perbaiki dan memberikan rekomendasi untuk memperbaiki temuan audit tersebut. Kemudian memberikan rekomendasi target tingkat kapabilitas yang akan dicapai kedepannya.

\section{Tindak lanjut (Follow Up)}

Tahap ini yang dilakukan adalah memberikan laporan hasil audit berupa rekomendasi tindakan perbaikan kepada pihak departemen TI UMN, untuk selanjutnya wewenang perbaikan menjadi tanggung jawab departemen TI UMN apakah akan diterapkan atau hanya menjadi acuhan untuk perbaikan dimasa yang akan datang.

Kemudian untuk mengukur nilai tingkat kapabilitas tata kelola dan manajemen teknologi informasi dilakukan dengan melakukan sejumlah tahapan/alur dari COBIT 5.0 yaitu, menentukan tujuan perusahaan yang kemudian dari hasilnya akan digunakan untuk mapping dengan enterprise goals COBIT 5.0. Langkah selanjutnya adalah mapping Enterprise Goals ke IT Goals yang hasilnya digunakan untuk mapping ke proses COBIT.
Pemberian nilai akan didasari dengan kriteria yang dimiliki dalam capability level. Tingkatan pada capability level adalah sebagai berikut [3]:

Tabel 1. Tingkat Kapabilitas

\begin{tabular}{|l|}
\hline Tingkat Model Kapabilitas \\
\hline $5-$ Optimising Process \\
\hline $4-$ Predictable Process \\
\hline $3-$ Established Process \\
\hline $2-$ Managed Process \\
\hline $1-$ Performed Process \\
\hline $0-$ Incomplete Process \\
\hline
\end{tabular}

Capability level memiliki 6 tingkatan, yang diawali dengan tingkat 0 , lalu tingkatan tertinggi berbobot 5 . Teknik pencapaian pada capability level bersifat mature, yang berarti organisasi perlu memenuhi level rendah untuk dapat mencapai level berikutnya. Misal, organisasi harus mendapatkan nilai $\geq 85 \%$ untuk dapat melanjutkan penilaian ke tingkat selanjutnya. Kategori penilaian dalam menggunakan capability level dapat dilihat pada Tabel 2[3].

Tabel 2. Kategori Penilaian

\begin{tabular}{|l|c|}
\hline \multicolumn{1}{|c|}{ Kategori Penilaian } & Nilai \\
\hline Tidak Dilakukan & $0-15 \%$ \\
\hline Dilakukan Sebagian Kecil & $16-50 \%$ \\
\hline Dilakukan Sebagian Besar & $51-85 \%$ \\
\hline Dilakukan Sepenuhnya & $86-100 \%$ \\
\hline
\end{tabular}

\section{ANALISIS DAN PEMBAHASAN}

Berikut hasil analisis dan pembahasan penelitian sesuai dengan tahapan audit Gallegos [2]:

1. Perencanaan (Planning)

Dalam tahap perencanaan ini dilakukan tiga tahapan COBIT 5.0 [4] yaitu mengidentifikasi Enterprise Goals dimana pemimpin departemen TI UMN diminta untuk mengurutkan 17 Enterprise Goals tersebut. Tahap selanjutnya adalah melakukan mapping Enterprise Goals ke IT Goals. Hasilnya terdapat 15 IT Related Goals yang menjadi prioritas. Tahap selanjutnya adalah melakukan mapping IT Goals ke dalam proses COBIT 5.0. Hasil dari mapping tersebut yaitu terdapat 24 jenis proses yang menjadi prioritas. Dari 24 jenis proses tersebut disaring menjadi 10 proses yang menjadi prioritas dari IT Related Goals nomor 1 sesuai dengan pilihan dari manajer departemen TI UMN dimana IT Related Goals nomor 1 merupakan prioritas utama bagi departemen TI UMN. Dari IT Related Goals nomor 1 tersebut menghasilkan 10 proses COBIT 5.0 yaitu, EDM01 (Ensure Governance Framework Setting and Maintenance), EDM02 (Ensure Benefits Delivery), APO01 (Manage the IT Management Framework), APO02 (Manage Strategy), APO03 (Manage Enterprise Architecture), APO05 (Manage Portfolio), PO07 (Manage Human Resources), APO08 (Manage Relationship), BAI01 (Manage Programmers and 
Projects), dan BAI02 (Manage Requirements Definition).

Adapun fokus utama dari masing-masing proses COBIT 5.0 sebagai berikut [3]:

a. EDM01 - Ensure Governance Framework Setting and Maitenance. Pada proses ini dilakukan analisa terhadap persyaratan untuk tata kelola TI di organisasi, prinsip-prinsip, proses dan praktek yang jelas terhadap tanggung jawab dan wewenang untuk mencapai visi, misi, tujuan dan objek organisasi.

b. EDM02 - Ensure Benefits Delivery. Pada proses ini mengoptimalkan kontribusi nilai bisnis dari proses bisnis, layanan dan asset TI yang dihasilkan dari investasi yang dilakukan oleh organisasi.

c. APO01 - Manage the IT Management Framework. Pada proses ini memperjelas visi, misi organisasi dan memelihara tata kelola TI. Menerapkan dan memelihara mekanisme untuk mengelola informasi dan penggunaan TI di organisasi dalam mendukung tujuan pengelolaan yang sejalan dengan prinsip dan kebijakan yang ada.

d. APO02 - Manage Strategy. Pada proses ini memberikan pandangan yang menyeluruh dari bisnis saat ini dan lingkungan TI, arah masa depan dan inisiatif yang diperlukan untuk lingkungan di masa depan.

e. APO03 - Manage Enterprise Architecture. Pada proses ini membangun arsitektur umum yang terdiri dari proses bisnis, informasi, data, aplikasi dan teknologi untuk mewujudkan strategi organisasi dan TI yang efektif dan efisien.

f. APO05 - Manage Portfolio. Pada proses ini menjelaskan tentang pengaturan strategi untuk investasi yang sejalan dengan visi, arsitektur dan karakteristik organisasi yang diinginkan dari investasi dan jasa terkait portofolio.

g. APO07 - Manage Human Resources. Pada proses ini menjelaskan tentang melakukan pendekatan terstruktur untuk memastikan struktur yang optimal, penempatan, hak keputusan dan keterampilan sumber daya manusia.

h. APO08 - Manage Relationship. Pada proses ini menjelaskan tentang pengelolaan hubungan antara bisnis dan TI secara formal dan transparan yang fokus pada pencapaian tujuan bersama. Mendasarkan hubungan saling percaya dan terbuka.

i. BAI01 - Manage Programmers and Projects. Pada proses ini menjelaskan tentang pengelolaan program dan projek dari investasi portofolio yang sejalan dengan strategi organisasi yang terkoordinasi.

j. BAI02 - Manage Requirements Definition. Pada proses ini mengidentifikasi solusi, menganalisa persyaratan sebelum akuisis atau pembuatan untuk memastikan kesesuaian dengan persyaratan strategis organisasi yang meliputi proses bisnis, aplikasi, informasi/data, infrastruktur dan layanan.

2. Pemeriksaan Lapangan (Field Work).

Pada tahap ini dilakukan pengumpulan informasi yang dilakukan dengan cara mengumpulkan data yang diterapkan dalam 3 metode yaitu, kuesioner, wawancara, dan observasi [5] yang kemudian akan menghasilkan bukti-bukti audit mengenai departemen TI UMN.

Berikut ini hasil total perhitungan tingkat kapabilitas departemen TI UMN yang diperoleh dari nilai kuesioner

Tabel 3. Total Perhitungan Kuesioner

\begin{tabular}{|c|c|c|c|c|}
\hline NO & PROSES & TOTAL & STATUS & $\begin{array}{c}\text { KETERANGA } \\
\mathbf{N} \\
\end{array}$ \\
\hline 1 & EDM01 & $81.84 \%$ & $\begin{array}{l}\text { Dilakukan } \\
\text { Sebagian Besar }\end{array}$ & $\begin{array}{l}\text { Proses berhenti } \\
\text { pada level } 1\end{array}$ \\
\hline 2 & EDM02 & $76.17 \%$ & $\begin{array}{l}\text { Dilakukan } \\
\text { Sebagian Besar }\end{array}$ & $\begin{array}{l}\text { Proses berhenti } \\
\text { pada level } 1\end{array}$ \\
\hline 3 & APO01 & $73.28 \%$ & $\begin{array}{l}\text { Dilakukan } \\
\text { Sebagian Besar }\end{array}$ & $\begin{array}{l}\text { Proses berhenti } \\
\text { pada level } 1\end{array}$ \\
\hline 4 & APO02 & $67.72 \%$ & $\begin{array}{l}\text { Dilakukan } \\
\text { Sebagian Besar }\end{array}$ & $\begin{array}{l}\text { Proses berhenti } \\
\text { pada level } 1\end{array}$ \\
\hline 5 & APO03 & $52.3 \%$ & $\begin{array}{l}\text { Dilakukan } \\
\text { Sebagian Besar }\end{array}$ & $\begin{array}{l}\text { Proses berhenti } \\
\text { pada level } 1\end{array}$ \\
\hline 6 & APO05 & $66.44 \%$ & $\begin{array}{l}\text { Dilakukan } \\
\text { Sebagian Besar }\end{array}$ & $\begin{array}{l}\text { Proses berhenti } \\
\text { pada level } 1\end{array}$ \\
\hline 7 & APO07 & $64.2 \%$ & $\begin{array}{l}\text { Dilakukan } \\
\text { Sebagian Besar }\end{array}$ & $\begin{array}{l}\text { Proses berhenti } \\
\text { pada level } 1\end{array}$ \\
\hline 8 & APO08 & $75.19 \%$ & $\begin{array}{l}\text { Dilakukan } \\
\text { Sebagian Besar }\end{array}$ & $\begin{array}{l}\text { Proses berhenti } \\
\text { pada level } 1\end{array}$ \\
\hline 9 & BAI01 & $56.33 \%$ & $\begin{array}{l}\text { Dilakukan } \\
\text { Sebagian Besar }\end{array}$ & $\begin{array}{l}\text { Proses berhenti } \\
\text { pada level } 1\end{array}$ \\
\hline 10 & BAI02 & $65.2 \%$ & $\begin{array}{l}\text { Dilakukan } \\
\text { Sebagian Besar }\end{array}$ & $\begin{array}{l}\text { Proses berhenti } \\
\text { pada level } 1\end{array}$ \\
\hline
\end{tabular}


Nilai Tertinggi: EDM01 $(80,84 \%)$

Nilai Terendah: APO03 (52.3\%)

Nilai rata-rata: $81.84 \%+76.17 \%+73.53 \%+67.72 \%$ $+52.3 \%+66.44 \%+64.2 \%+75.19 \%+56.33 \%+$ $65.2 \% / 10=678,92 \% / 10=67,9 \%$ (Dilakukan Sebagian Besar)

\section{Pelaporan (Reporting)}

Kuesioner yang digunakan pada penelitian ini ditujukan kepada 2 responden kepercayaan IT manager yaitu pada coordinator divisi IT support dan IT development yang bertujuan untuk melengkapi penelitian dari sudut pandang karyawan dalam departemen TI UMN. Kuesioner yang digunakan memiliki 345 butir pernyataan berdasarkan standar COBIT 5.0.

Pada penelitian ini, penulis menggunakan teknik wawancara yaitu berkomunikasi langsung, dalam hal ini berkomunikasi yang di maksud adalah berbincangbincang, mengajukan 26 pertanyaan yang berguna mendapatkan informasi mengenai departemen TI UMN yang dilakukan kepada IT manager UMN (Bapak Dwi Kristiawan).

Observasi dilakukan penulis yaitu dengan berhadapan langsung dengan situasi dan kondisi kerja dari departemen TI UMN yang dilakukan bersamaan dengan pembagian kuesioner, pengambilan kuesioner dan wawancara yang dilakukan didalam ruang kerja departemen TI UMN, untuk melihat seperti apa kondisi lingkungan, bagaimana proses kerja dan apa saja yang mendukung kelancaran kerja departemen TI UMN seperti orang-orang yang terlibat langsung dalam pembuatan dan pemeliharaan sistem dan perangkat lunak yang berkaitan dengan departemen TI UMN.

Berdasarkan kuesioner, wawancara dan observasi, berikut ini hasil rekomendasi untuk Departemen TI UMN.

Tabel 4. Rekomendasi Perbaikan
\begin{tabular}{|l|}
\hline Rekomendasi Perbaikan \\
\hline APO03 \\
\hline - Sebaiknya sumber daya dan strategi bisnis yang di \\
gunakan dipersiapkan dengan matang terlebih dahulu \\
dan dikonfirmasikan kepada setiap tenaga kerja. \\
- Sebaiknya sebelum melaksanakan proyek, menejer \\
memberikan penjelasan yang terperinci mengenai \\
proyek yang akan di kerjakan pada karyawan dan terus \\
memonitor setiap langkah kerja dari karyawan agar \\
semua tindakan sesuai prosedur dan peraturan yang di \\
tetapkan. \\
Memberikan perlindungan terhadap kabel-kabel \\
eksternal supaya dapat menghindari kerusakan - \\
kerusakan dan jika diperlukan, letakkan kabel eksternal \\
di bawah tanah agar lebih aman. \\
- Sebaiknya meletakkan tabung pemadam kebakaran di \\
dalam ruangan TI agar mudah dijangkau ketika terjadi \\
kebakaran dan tidak perlu keluar dari ruangan untuk \\
\hline
\end{tabular}

\begin{tabular}{|l|}
\hline \multicolumn{1}{|c|}{ Rekomendasi Perbaikan } \\
\hline memadamkan api di dalam ruangan. \\
\hline APO07 \\
\hline - Membuat kebijakan mengenai tata tertib karyawan \\
atau staf masuk ke dalam ruangan TI untuk tidak \\
membawa makanan dan minuman untuk mengurangi \\
resiko kerusakan. \\
Memberi training tambahan pada pegawai, sehingga \\
dapat menambah wawasan pegawai. \\
\hline BAI01 \\
\hline - Sebelum melakukan tugas, identifikasi terlebih dahulu \\
keinginan dan kebutuhan stakeholder secara terperinci \\
dan disebarkan pada setiap tenaga kerja \\
- Sebaiknya sebelum melakukan proyek, melakukan \\
analisis secara terperinci kemungkinan resiko yang akan \\
terjadi selama pelaksanaan proyek agar proyek dapat \\
selesai sesuai target secara maksimal. \\
\hline BAI02 \\
\hline - Membuat laporan secara resmi yang disetujui oleh \\
stakeholder dan user mengenai proyek yang akan \\
dilakukan secara detail, agar tidak ada pihak yang \\
dirugikan.
\end{tabular}

Berdasarkan target tingkat kapabilitas yang sesuai dengan permintaan pihak departemen TI UMN yaitu pada level 2, rekomendasi agar mencapai tingkat kapabilitas level 2 yang disimpulkan sebagai berikut. Sebaiknya pihak Departemen TI UMN mengidentifikasi tujuan, me-monitor, memelihara, menyediakan sumber daya dan informasi, menjaga hubungan yang baik dengan setiap pihak yang terlibat dan mengalola setiap dokumentasi mengenai kerangka kerja, strategi, arsitektur, portofolio, sumber daya manusia, dan proyek perusahaan.

\section{Tindak Lanjut (Follow $U p$ )}

Rekomendasi yang menjadi opini auditor dikomunikasikan kepada kepala departemen TI Universitas agar dapat ditindaklanjuti proses perbaikan untuk bisa mencapai target level, yaitu level 2.

\section{SIMPULAN}

Berdasarkan penelitian, pembahasan dan analisis dari kuesioner, obesrvasi dan wawancara mengenai tahapan audit yang telah dilakukan, dapat diambil kesimpulan untuk setiap proses COBIT 5.0 yang di gunakan sebagai berikut:

1. Pada proses EDM01 membahas tentang memastikan pengaturan dan pemeliharaan kerangka perusahaan. Pengukuran Tingkat Kapabilitas EDM01 berada pada level 1 dengan skor $81,84 \%$ dimana proses ini merupakan proses yang memiliki skor paling tinggi.

2. Untuk proses EDM02 membahas tentang memastikan menyampaian manfaat yang dicapai departemen TI. Pada proses ini, pengukuran Tingkat Kapabilitas berada pada level 1 dengan skor $76,17 \%$. Proses ini dilakukan sebagian besar 
oleh departemen TI UMN akan tetapi belum bisa mencapai level berikutnya.

3. Untuk penerapan proses APO01 yang membahas tentang mengelola menejemen framework IT memiliki pengukuran Tingkat Kapabilitas berada pada level 1 dengan skor $73,53 \%$.

4. Pada penerapan proses APO02 yang membahas tentang pengelolaan strategi yang digunakan di dalam departemen TI. Pada proses ini pengukuran Tingkat Kapabilitas hanya mencapai level 1 dengan skor $67,72 \%$.

5. Pada proses APO03 membahas tentang pengelolaan arsitektur perusahaan. Pada proses ini mencapai level 1 dengan skor paling rendah dari proses yang lain yaitu $52,3 \%$.

6. Untuk penerapan proses APO05 memilki tingkat kapabilitas pada level 1 dengan skor $66,436 \%$. Proses APO05 ini membahas tentang pengelolaan portfolio dalam departemen TI.

7. Untuk penerapan proses APO07 memilki tingkat kapabilitas pada level 1 dengan skor 64,199\%. Proses APO07 ini membahas tentang pengelolaan sumber daya manusia di dalam departemen TI.

8. Untuk penerapan proses APO08 memilki tingkat kapabilitas pada level 1 dengan skor $75,187 \%$. Proses APO08 ini membahas tentang pengelolaan hubungan (relationship) antara internal dan eksternal IT.

9. Pada proses BAI01 membahas tentang pengelolaan program dan proyek yang dilakukan departemen TI. Proses ini memiliki skor 56,32\% yang berarti hanya mencapai tingkat kapabilitas level 1.

10. Pada proses yang terakhir yaitu BAI02 membahas tentang pengelolaan definisi permintaan dalam departemen TI. Proses ini memiliki skor $65,2 \%$ yang berarti hanya mencapai tingkat kapabilitas level 1.

\section{DAFTAR PUSTAKA}

[1] Amnah. 2014. Analisa Proses Audit Sistem Informasi Biro Manajemen Asset dan Logistik Menggunakan Framework COBIT 4.1 pada Institut Informatika dan Bisnis Darmajaya Bandar Lampung. Jurnal Informatika, Volume 14 Nomor 1, Juni 2014

[2] Gallegos, F. 2008. Information Technology Control and Audit, Third Edition. USA: CRC Press.

[3] ISACA. COBIT 5.0. United States of America: IT Governance Institute, 2013.

[4] ISACA. COBIT 5: A Business Framework for the Governance and Management of Enterprise IT. 2012.

[5] Sugiyono. "Memahami Penelitian Kualitatif". Bandung: ALFABETA, 2012. 